
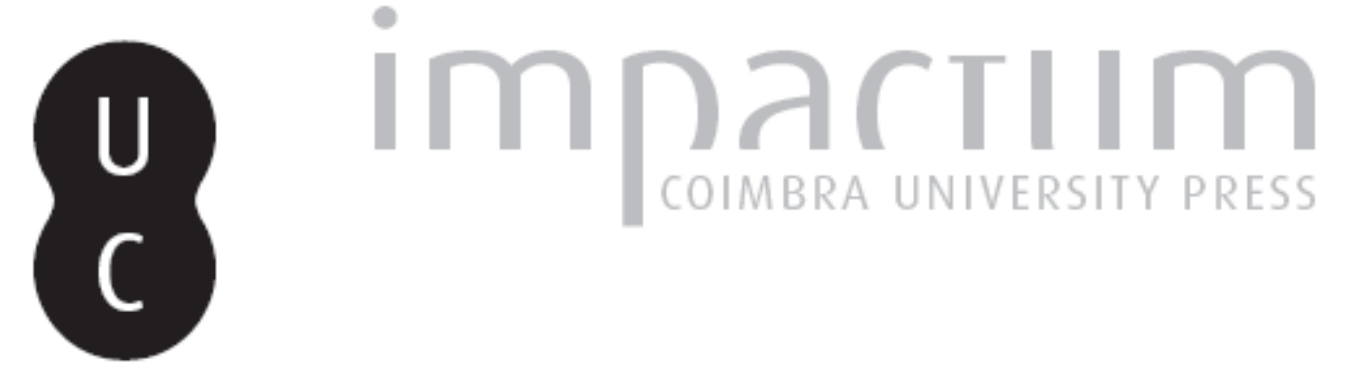

\title{
[Recensão a] OLIVEIRA, R. R. (2013) - Pólis e Nómos: o problema da lei no pensamento grego
}

Autor(es): $\quad$ Tabone, Danilo Andrade

Publicado por: Annablume Clássica; Imprensa da Universidade de Coimbra

URL

persistente:

URI:http://hdl.handle.net/10316.2/27888

DOI:

DOI:http://dx.doi.org/10.14195/1984-249X_12_20

Accessed : $\quad$ 26-Apr-2023 10:44:35

A navegação consulta e descarregamento dos títulos inseridos nas Bibliotecas Digitais UC Digitalis, UC Pombalina e UC Impactum, pressupõem a aceitação plena e sem reservas dos Termos e Condições de Uso destas Bibliotecas Digitais, disponíveis em https://digitalis.uc.pt/pt-pt/termos.

Conforme exposto nos referidos Termos e Condições de Uso, o descarregamento de títulos de acesso restrito requer uma licença válida de autorização devendo o utilizador aceder ao(s) documento(s) a partir de um endereço de IP da instituição detentora da supramencionada licença.

Ao utilizador é apenas permitido o descarregamento para uso pessoal, pelo que o emprego do(s) título(s) descarregado(s) para outro fim, designadamente comercial, carece de autorização do respetivo autor ou editor da obra.

Na medida em que todas as obras da UC Digitalis se encontram protegidas pelo Código do Direito de Autor e Direitos Conexos e demais legislação aplicável, toda a cópia, parcial ou total, deste documento, nos casos em que é legalmente admitida, deverá conter ou fazer-se acompanhar por este aviso.

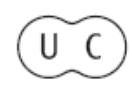


jan/jun

\begin{tabular}{c}
2014 \\
\hline issn 2179-4960 \\
e-issn 1984-249-X
\end{tabular}
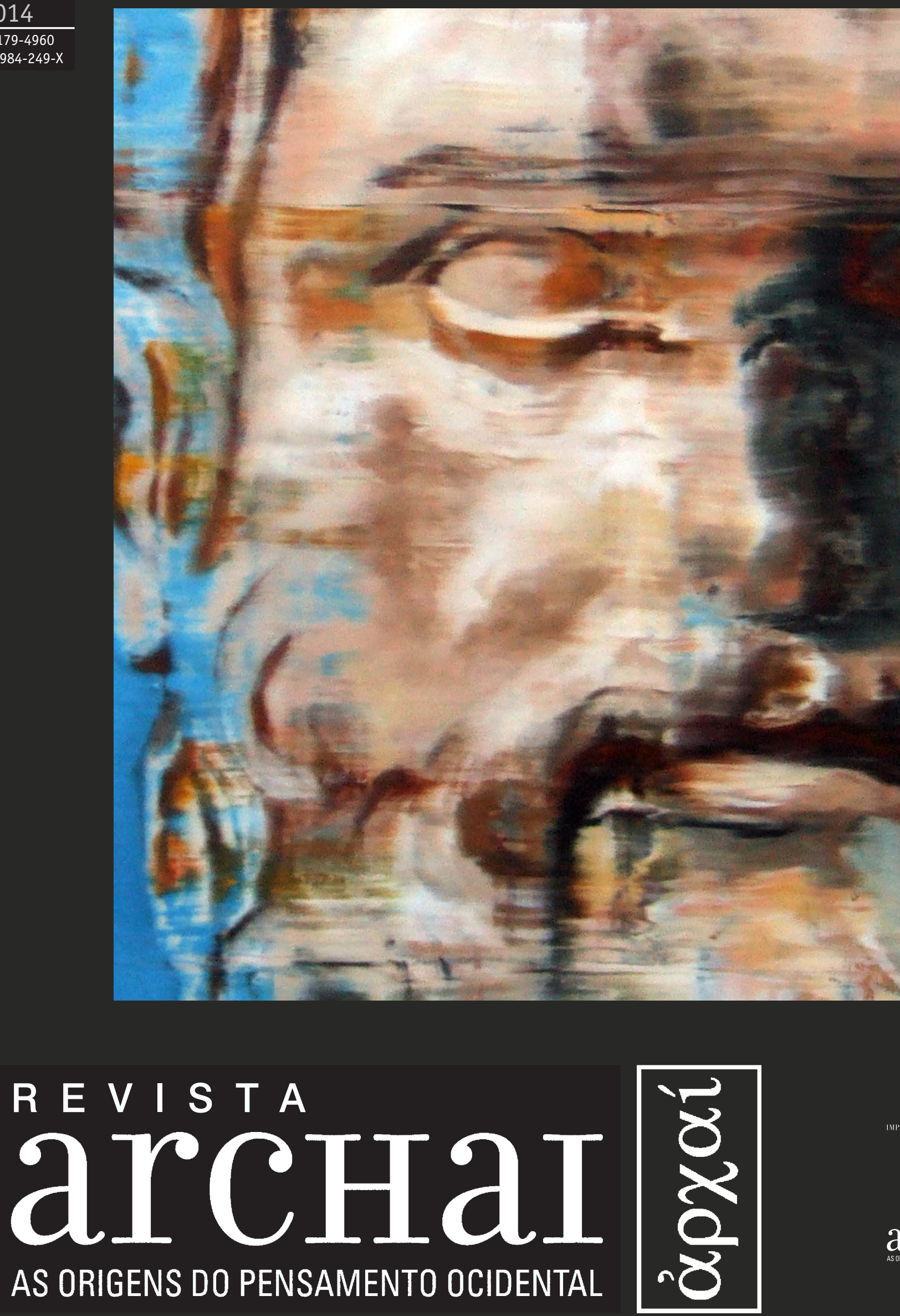
ARCHAI JOURNAL: ON THE ORIGINS OF WESTERN THOUGHT

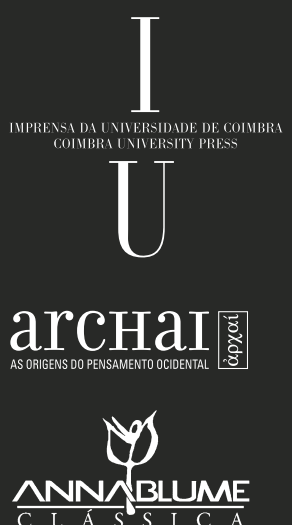




\section{TABONE, D. A. (2013). RESENHA. OLIVEIRA, R. R. (2013). PÓLIS E NÓMOS: 0 PROBLEMA DA LEI NO PENSAMENTO GREGO. LOYOLA. SÃO PAULO.}

Mestre em Arqueologia, Museu de Arqueologia e Etnologia da Universidade

de São Paulo
Danilo Andrade Tabone*

A obra do filósofo Dr. Richard Romeiro Oliveira objetiva explicitamente, através de "reflexões de caráter jurídico e ético nas obras de variados autores" (p. 9), fornecer "um panorama dos principais momentos que marcaram o desenvolvimento [da] reflexão legal na Hélade. Trata-se, pois, de tentar acompanhar o nascimento e as principais transformações ou vicissitudes do pensamento jurídico no mundo grego" (p. 13, grifo meu). Desde o título se estabelece a proposta de pensar a relação entre a noção de nómos (lei) e a emergência da pólis. Este tema mais amplo é tratado no primeiro capítulo, 'A formação da pólis e a descoberta da lei escrita', onde, em uma abordagem chamada de "histórico-genética", o autor percorre o desenvolvimento das concepções legais desde o período micênico até a época clássica, relacionando-as com a origem da pólis e o desenvolvimento da democracia em Atenas.

Os dois capítulos seguintes tratam mais especificamente das especulações filosóficas a respeito da lei no curso do séc. V a.C.: no capítulo 2, 'A oposição sofística physis x nómos e a desconstrução filosófica da ideia de lei', aborda a oposição entre esses dois conceitos no pensamento sofista, que passa a questionar a soberania do nómos como era até então entendida pelos pré-socráticos, a qual passa a ser vista como mera criação humana. 
capítulo 3 'Lei e racionalidade em Platão', trata da questão no pensamento político de Platão, onde 0 tema aparece como uma resposta que se contrapõe à relativização defendida pelos sofistas.

A partir do título temos uma questão que é de ordem histórica/cultural: a emergência da pólis e da noção de nómos. Mas ao reduzir o fenômeno pensamento unicamente àquele presente no discurso filosófico, pretendendo, por exemplo, que uma "crise [da] tradição legalista e nomotética [surja] a partir da ascensão do convencionalismo sofístico" (p. 13), o autor se afasta de uma concepção de pólis como fenômeno cultural mais amplo. 0 pensamento no mundo grego Antigo não se resumia à Filosofia; redução que é estruturada e por conseguinte acaba estruturando uma série de equívocos sobre as culturas gregas Antigas. Esta resenha, por isso, assumirá uma posição crítica com relação aos conceitos adotados tanto para pólis quanto para nómos.

A abordagem "histórico-genética" adotada pelo autor no primeiro capítulo, acaba por redundar em uma evolução de tipo teleológico, culminando em uma secularização/racionalização do pensamento grego na Atenas democrática do séc. $V$ a.C. Baseado em Jean-Pierre Vernant (1970), o autor percebe uma pólis aberta a racionalização, com a transformação de um "saber secreto de tipo místico" de época micênica/homérica ${ }^{1}$, onde o "direito" estava subordinado ao poder do basileús/ánax, em um corpo de verdades divulgadas, que passam a ser escritas, constituindo um "direito positivo".

Isto traz alguns problemas que dizem respeito à natureza da pólis. Como falar em 'secularização' em Estados que não tem cleros, mas religiões próprias, que sorteiam seus magistrados (cargos que são também religiosos), onde procedimento e penalidade, inclusive o julgamento e a condenação por homicídio, são governados pelo medo do miásma - e não por se conceberem 'direitos humanos' - que lapidam anualmente um pharmakós, que processam por impiedade? (DELCOURT, 1964). Em outras palavras, póleis enquanto comunidades que se definem pela participação comum de seus membros no culto. E ao falar na emergência de um "espaço público" como prova de uma "nova forma de sociabilidade", secularizada (p. 17ss), mas desconsiderando a evidência da Arqueologia, o autor se priva de reconhecer a importância das áreas sacras na divisão do território público das póleis. Vale lembrar que na ágora de Atenas estavam as estátuas dos heróis epônimos, o altar de Zeus Agoraios, dos Doze Deuses, de Ares, entre outros monumentos sacros que também dominavam a paisagem ao redor, como o Hefesteion e o próprio complexo da acrópole, o que mostra a inconsistência da tese que procura ver a pólis como um mundo secularizado.

Segundo ponto. Nesta imagem de uma pólis secularizada surge o nómos enquanto norma humana em oposição ao thémis/thesmós como norma de origem divina; fenômeno que se relaciona com a origem de uma pólis entendida como uma "comunidade citadina e urbana" (p. 31), onde há descentralização e coletivização do poder. Em outras palavras, é afirmado que o surgimento do "direito positivo" se relaciona com a emergência da democracia em Atenas, entendida como uma "forma superior de organização do poder" (p. 41).

Para Oliveira, o elemento gerador de "mudanças no paradigma legalista" (p. 64) rumo à "secularização da lei" foi o surgimento do debate no contexto democrático, quando o nómos teria passado a ser entendido como "mero decreto humano". 0 autor busca sinais dessa mudança de paradigma no discurso trágico. Em sua análise da Antígona de Sófocles, a presença de um conflito entre dois princípios de justiça (ambos nomeados como nómos) - o direito dos homens (encarnado em Creonte, o rei de Tebas) e o direito dos deuses e sua Justiça (encarnado em Antígona) - é visto como evidência para alegar a secularização da noção de lei. Mas em uma análise mais cuidadosa, onde se considere a tragédia sofocleana em seu contexto, entende-se que o embate acontece entre uma lei ancestral/ divina e a lei de Creonte, que aparece virtualmente como tirano (aparecem os termos basileús, ánax e estratego), este sim, para os atenienses, em conflito com as leis divinas. No diálogo entre Creonte e seu filho Hemon, este questiona o decreto do pai afirmando que a "cidade de Tebas" com ele não

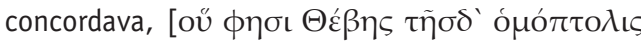
$\lambda \varepsilon \omega ́ \omega]$ (Soph. Ant. 732), ao que o rei questiona se

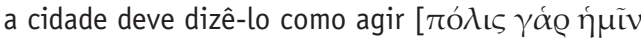

1. Ao reconhecer um fundo micênico nos poemas homéricos, o autor confunde esse passado com o "mundo homérico", eximindo-se, por isso, de recorrer a fontes de época micênica, e de perceber que o mundo onde emergem as póleis nos séculos IX-VIII a.C., e que se reflete nos épicos, corresponde a outra realidade que não a micênica. 


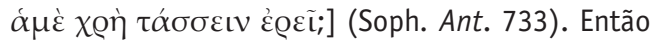
Hemon lhe responde que "não há cidade que seja de um só" (Soph. Ant. 738-739). Vale lembrar o coro no início da peça, que ao exaltar os feitos humanos,

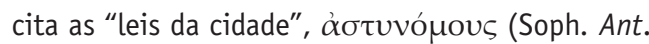
355), a mesma cidade que Creonte não quis ouvir. No final da tragédia descobrimos que os tebanos haviam reconhecido a importância de se observar as leis dos deuses, e que foi Creonte, governando sozinho, que não a reconheceu.

Do ponto de vista do ateniense Sófocles está em questão a lei do tirano como um governante injusto e peremptório, apresentando a tirania como um regime nocivo, onde inexiste o debate de ideias, critério tido como essencial para se chegar às leis justas. Mas esta noção não dá conta do fenômeno no "pensamento grego" como um todo, primeiro ao desconsiderar que a pólis nunca deixou de ser um mundo essencialmente agrário - e que a urbanização de Atenas esteve longe de ser a regra para as demais póleis, o que não as impediu de terem leis escritas (nómoi) votadas em Assembléias (como as póleis e os éthne da Beócia ou da Arcádia, onde a fundação de Megalópolis para servir de centro da Federação foi um fenômeno relativamente tardio, na metade do séc. IV a.C.); também desconsidera o fato de muitas póleis nunca terem experimentado o regime democrático: Cirene, no norte da África, sempre foi uma monarquia; e diversas póleis viveram sob regimes oligárquicos, aristocráticos ou em tiranias durante grande parte de sua história, muitas das quais contando com a aprovação de contingentes expressivos da população - caso da aclamação popular de Hieron de Siracusa (Diodoro 11.26.5-6; 67.2.3; HIRATA, 2010, p. 27) - o que leva a crer que os gregos viam vantagens também neste tipo de governo e que a sua condenação fosse parte de um discurso construído por pensadores atenienses de época clássica (LEWIS, 2006). Assim, não é possivel definir a pólis ou o surgimento de um “direito positivo" exclusivamente pela existência de participação política (democracia).

É notável, com isto, que não havia unidade substancial na experiência jurídica do mundo grego, mas sim diversidade local - sobre o que Finley (1989) chamou atenção em um ensaio paradigmá- tico - o que, então, não permite que se fale em direito grego, ao modo como é possivel falar em um direito romano, e o que a citação do De Legibus de Cícero na epígrafe do livro erroneamente sugere.

De toda forma, estudiosos da lei na Grécia Antiga como Barbara Agnastou-Canas (2001) e Ilias Arnatoglou (2003) têm ressaltado o caráter sagrado dos nómoi também em póleis democráticas, onde se acreditava que as leis eram inspiradas pelos deuses através do debate público - o debate se apresenta como elemento de sacralização da lei e não de secularização. Assim como a sua inscrição, o que Rosalind Thomas (1995) reconhece como uma busca por monumentalidade e proteção divina, na medida em que se acreditava que 0 ato de inscrever as leis em uma pedra as faria desfrutar da mesma respeitabilidade que as normas consuetudinárias, que não eram questionadas.

0 nómos possuía um caráter de permanência, de substância da norma. Em Atenas, ao seu lado, surge outro termo no período Clássico, o psefisma (decreto), para se referir a medidas circunstanciais e provisórias, mas que não poderiam ir contra o estabelecido nos nómoi (AGNASTOU-CANAS, 2001, p. 105). A distinção era formal e consistia na diferença em seus respectivos modos de elaboração, assim como nos procedimentos utilizados para controlar sua conformidade com a nomima (conjunto de leis ou costumes) que formava a politéia (constituição), a ordem jurídica da cidade (sobre esta discussão, cf. HANSEN, 1978, p. 315-330), instituída desde as reformas de Drácon, Sólon e Clístenes - que inclusive eram tidos como homens excepcionais (heróis) e cujas leis, conhecidas como thesmoi, estavam acima da mera criação humana (cf. MOSSÉ, 1979). São conhecidos outros casos de leis que buscavam assegurar a permanência da ordem jurídica, evitando a promulgação de leis conflitantes e a subversão da politéia, como a de Zaleucos em Locres Epizefiri (Estrabão. 6.1.8), de c. 663 a.C., ou outra em Elis (Nomina I, 108) do séc. VI a.C. Esta permanência do nómos estava imbuída por uma ideia de sacralidade: a nomina garantia a estabilidade da politéia, reflexo da ordem cósmica, a qual uma vez ameaçada poderia redundar em desequilíbrio, hýbris que engendra "homens fortes", caminho para a tirania (Teógnis 43-44) - ou uma stásis (51-52), entendida 
como "caos" (Políbio 4.21.4; 21.11), no sentido de 'ausência' de possibilidade de civilização, que é justamente o que os thésmoi preservam, “o que está fixado". Em certo sentido, o nómos garante as condições para que o thésmos/thémis seja observado, sendo possível a vida civilizada - ao mesmo tempo urbana e agrária.

Uma das raízes dessa concepção da pólis e da lei provém das fontes consideradas pelo autor. Tal estudo não pode desconsiderar a evidência literária, mas muito menos a da Epigrafia, testemunho privilegiado - e sem intermediários - que fornece nomes de comunidades cívicas e étnicas, textos integrais de decretos, tratados e regulações sobre instituições e festas religiosas, e que permite a consideração dos usos, dos significados e das "transformações ou vicissitudes do pensamento jurídico" em uma relação direta com a realidade das póleis. A obra falha, assim, pela ausência de erudição documental e filológica, assim como hermenêutica.

Desde a renovação dos estudos sobre a lei por Louis Gernet (1968), o enfoque antropológico, do que a análise semântica dos textos e dos termos foi um método profícuo, possibilitou perceber a relação entre lei e poder como exercido no interior da sociedade. Por outro lado, não é mais possivel que este enfoque desfaça a História (suspendendo o tempo) e se feche em uma cidade (Atenas), excluindo os conflitos políticos no interior das póleis. É necessário, assim, pôr de lado a oposição existente entre pólis como 'comunidade' ou como 'Estado' (koinónia ou politéia), em um enfoque antropológico que também considere o político, entendido não enquanto práticas específicas, mas como domínio difuso nas demais instituições sociais, incluso religiosas.

\section{Referências Bibliográficas}

ANAGNASTOU-CANAS, B. (2001) Le droit grec: de la cité classique à l'Egypte hellénistique et romaine. École Pratique des Hautes Études. Section des Sciences Historiques et Philologiques, Ano 15.

ARNATOGLOU, I. (2003) Leis da Grécia Antiga. São Paulo, Odysseus.

DELCOURT, M. (1964) Vernant (J.-P.), Les origines de la pensée grecque. Revue Belge de Philologie et d'Histoire, v. 42, n.2.
FINLEY, M. (1989) 0 problema da unidade do direito grego. In. Uso e abuso da história. São Paulo, Martins Fontes.

GERNET, L. (1968) Droit et prédroit, Droit et ville dans l'antiquité grecque. In. Anthropologie de la Grèce Antique. Paris, François Maspero.

HANSEN, M. H. (1978) Nomos and Psephisma in FourthCentury Athens. GRBS, v. 19.

HANSEN, M. H. (1993) The Ancient Greek City-State.

HIRATA, E. F. V. (2010) Monumentalidade e representações do poder tirânico no ocidente grego. In. Gabriele Cornelli (ed). Representações da Cidade Antiga: categorias históricas e discursos filosóficos. Brasília, Coimbra, Centro de Estudos Clássicos e Humanísticos, Classica Digitalia Vniversitatis Coninbrigensis.

LEWIS, S. (2006) Ancient Tyranny. Edimburgo, Edimburgh University Press.

MOSSÉ, C. (1979) Comment s'élabore un mythe politique: Solon, "père foundateur" de la démocratie athénienne. Annales ESC, v. 34 , n. 3.

MURRAY, 0. (1992) Cités des raison. In. Simon Price (ed.). La Cité grecque d'Homère à Alexandre. Paris, La Découverte.

POLIGNAC, F. (1997) Anthropologie du politique en Grèce ancienne. Annales ESC.

THOMAS, R. (1995) Writing in stone? Liberty, equality, orality and codification of Law. Bulletin of the Institute of Classical Studies, v. 40, n. 1.

VAN EFFENTERRE, H.; DEMARGNE, J. (1937) Recherches à Dréros, II Les inscriptions archaïques. $B C H$, v. 61.

VERNANT, J-P. (1970) Origens do pensamento grego. Rio de Janeiro, Difel.

Artigo recebido em agosto de 2013, aprovado em novembro de 2013. 